\title{
Biopolítica: o poder médico e a autonomia do paciente em uma nova concepção de saúde
}

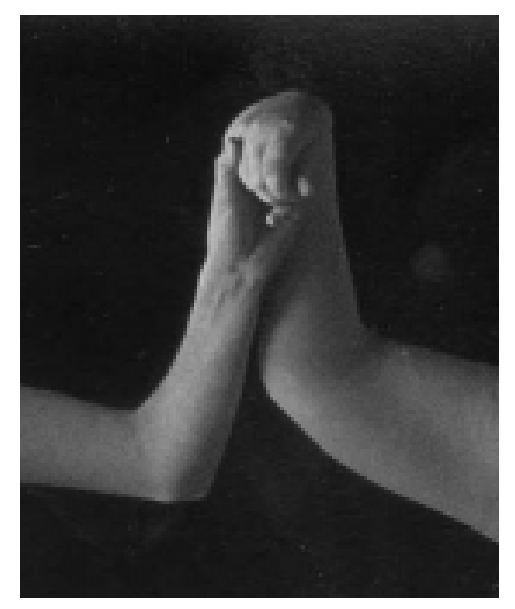

André Martins ${ }^{1}$

MARTINS, A. Biopolitics: medical power and patient autonomy in a new conception of health, Interface -

Comunic., Saúde, Educ., v.8, n.14, p.21-32, set.2003-fev.2004.

This paper proposes an articulation between Foucault's critique of what he called the "authoritarian medicalization of bodies and diseases" and Spinoza's concept of the enhancement of the power to act, within the framework of a reflection on the issue of individual autonomy. To this end, a critical and genealogical discussion of the concept of health and of cure as found in current medical practice is presented, as well as a discussion of medical power and the mechanistic and scientistic ideas concerning the body and the diseases attached to it. This idea is in contrast to Canguilhem's notion of health as being linked to normativeness and of cure as being connected with rehabilitation. Based on this change of indicators, current medical practices are reconsidered, as well as the idea of encouraging health and prevention.

KEY WORDS: Power; medicalization; patient autonomy; biopolitics; ethics.

Propõe-se articular a crítica de Foucault ao que este chamou de "medicalização autoritária de corpos e doenças" ao conceito de Espinosa de aumento da potência de agir, tendo como horizonte uma reflexão sobre a questão da autonomia dos indivíduos. Para isso, desenvolve-se uma reflexão crítica e genealógica sobre a concepção de saúde $e$ de cura presentes na prática médica atual, assim como sobre o poder médico e a concepção mecanicista $e$ cientificista do corpo e da enfermidade a ele atrelada. A esta concepção contrapõe-se uma noção canguilhemiana de saúde ligada à normatividade e de cura ligada à reabilitação. A partir destes deslocamentos, repensam-se as práticas médicas atuais, assim como as concepções de promoção da saúde e de prevenção.

PALAVRAS-CHAVE: Poder; medicalização; autonomia do paciente; biopolítica; ética.

${ }_{1}^{1}$ Professor do Núcleo de Estudos de Saúde Coletiva (NESC) e do Departamento de Medicina Preventiva da Universidade Federal do Rio de Janeiro (UFRJ); colaborador do Programa de Pós-Graduação em Filosofia do IFCS/UFRJ; coordenador da área de Ciências Humanas \& Saúde do Programa de Pós-Graduação em Saúde Coletiva do NESC/UFRJ. <andremar@nesc.ufrj.br> 


\section{Introdução}

Na prática médica atual - tal como descrito por Foucault em sua conferência de $1974^{2}$, proferida no IMS/UERJ, intitulada "O nascimento da Medicina social" - os doentes tendem a perder "o direito sobre o seu próprio corpo, o direito de viver, de estar doente, de se curar e morrer como quiserem", $e$ por conseguinte sua autonomia (Foucault, 1979, p.96). Autonomia no que diz respeito não somente à forma como serão tratados, como também à determinação de seu modo de vida e de conduta. Autonomia, portanto, aqui entendida não no sentido kantiano de uma responsabilização moral, de uma elite sobre aqueles acusados de não seguir a norma ou a razão, mas no sentido espinosano de uma assunção de si de corpo e alma, no respeito à realidade presente de cada um.

Neste sentido, pergunta-se Foucault: que significado têm alguns ritos religiosos populares,

senão uma espécie de resistência difusa à medicalização autoritária de seus corpos e doenças? Em lugar de ver nessas práticas religiosas um fenômeno residual de crenças arcaicas ainda não desaparecidas, não serão elas uma forma atual de luta política contra a medicalização autoritária, o controle médico? (Foucault, 1979, p.97)

A Medicina se tornaria assim uma moral, tendo como critério e supremo Bem a saúde. Ou melhor, um ideal de saúde. Mas que fronteira pode haver entre tal ideal de saúde, alienante e submisso ao poder médico, e algo da ordem da saúde, não ideal, mas efetiva, vinculado à potência singular da pessoa?

Em outras palavras, a autonomia dos indivíduos na coletividade estaria recuperada simplesmente por uma "resistência" - ou reação - às imposições de uma Medicina oficial científica?

\section{Medicina científica?}

A Medicina contemporânea orgulha-se de considerar-se 'científica'. Mas, o que quer dizer 'científico'? O que a Medicina entende por isso?

A Ciência caracteriza-se, desde seus primórdios com Aristóteles, como um conhecimento que se propõe a ter a capacidade de universalização, isto é, de ser universalizado. Como mostrara Aristóteles, não há Ciência do particular, no sentido de que o conhecimento do particular enquanto particular não pode ser estendido a outros particulares, de modo que se torna um conhecimento não aplicável senão ao próprio particular do qual fora extraído. Não há lei que valha somente para um caso - esta é a idéia. Um conhecimento, para que seja científico, deve poder abranger um espectro de casos que ultrapasse aqueles diretamente estudados. Assim o é, para ficarmos com um exemplo evidente, com as leis da física. Certo, no auge da crença na Ciência pensava-se - e talvez ainda haja hoje quem pense assim que a Ciência é válida universalmente, entenda-se, para todo o universo. Crença que tivera como conseqüência diversos modos de preconceito $e$ autorizara diversos tipos de ações invasivas. Entendamos hoje que a Ciência 
não é universal; todavia, seu caráter universalizante continua válido; dizemos apenas que um conhecimento é científico quando é válido para um determinado universo em questão. Para ser científico, tal conhecimento precisa ser extensível para além do caso estudado, mas já sabemos que não será extensível para todo o universo no sentido absoluto. Ao contrário, é necessário determinar as condições de extensibilidade do conhecimento obtido cientificamente para que ele continue a ter validade científica.

O caráter de universalização relativa, contudo, define as Ciências em geral, não somente as ditas 'Ciências duras' - afinal, a exemplaridade de um estudo de caso pode servir para a compreensão de outros casos análogos ou semelhantes. O núcleo duro da Ciência se dá por seu instrumento que permite uma universalização maior: a matemática, isto é, o formalismo matemático. A Ciência, neste sentido 'duro', trabalha necessariamente com reduções: reduz o objeto complexo real a sistemas formais. Esta formalização permite uma maior universalização, mas perde, ipso factu, as características singulares do objeto estudado. A vantagem disso, poder ser estendido a um universo maior, por não carregar características singulares dos objetos iniciais; a desvantagem, a mesma perda destas singularidades (Morin, 1994; 1991; Deleuze \& Guattari, 1992; Martins, 1999).

Ainda assim, esta operação de redução e posterior universalização deve ser observada com atenção, pois toda universalização, como vimos, é relativa, isto é, não é extensível ou válida indiferentemente para todo e qualquer caso. Aqui reside o primeiro problema: uma pesquisa feita com pessoas de uma certa cultura - a norte-americana, por exemplo -, será universalizável para além do universo daquela cultura? Sempre? Sob quais condições ou critérios sim, ou não? Observamos isso aqui em nosso país periférico? Não necessariamente, nem sempre, a princípio não. Este problema, evidentemente, não é apenas um problema de validade propriamente científico, mas também fundamentalmente político.

Do mesmo modo: uma pesquisa feita com financiamento de indústrias, sobre o que elas próprias produzem, são isentas? Pesquisas sobre uma suposta não nocividade do asbesto para os trabalhadores, financiadas por uma indústria de amianto, serão científicas? (Bittar, 2000) Uma indústria farmacológica que faz pesquisas que mostrem os supostos benefícios de suas drogas sem contextualizar as demais questões envolvidas em seu uso, estas serão científicas? O problema é que a resposta aqui é: sim, pode ser científica. E isso depende de quê? Simplesmente do fato de tal pesquisa ter seguido critérios formais rigorosos de redução. O que quero enfatizar é que seguir o método científico de redução não garante que o resultado encontrado corresponda à realidade. $\mathrm{O}$ que é científico segue normas que numa determinada época e contexto são consideradas científicas, formais, protocolares; não quer dizer que seja verdadeiro. A cientificidade não é índice de veracidade.

Ou seja, a grande confusão que é feita se dá entre pensar que seguir métodos pré-estabelecidos de redução formal é o mesmo que 'dizer a verdade'. A Ciência passa assim a ser tomada não mais 
cientificamente, mas como um oráculo que revelaria a verdade do objeto estudado. Não é assim. Ao contrário, se a Ciência dissesse a verdade não seria Ciência, mas dogma, isto é, o contrário do que ela se propõe a ser. Se seguir o método levasse à verdade, esta estaria contida no resultado obtido e a própria Ciência não seria mais necessária. Seria um dogma, uma crença na verdade, não a criação de suportes de compreensão de realidades.

Em suma, o que caracteriza a Ciência é seu caráter redutor. Na redução, perde-se muitos aspectos do objeto real, tanto aspectos não quantificáveis por natureza (e não menos reais e efetivos por isso), quanto outros aspectos quantificáveis mas que não entraram no estudo em questão. Sendo assim, os resultados da redução necessariamente serão incompletos, refletirão uma única perspectiva, ou algumas poucas. Mas assim é a Ciência, e disso ela tira suas vantagens e ao mesmo tempo encontra seus limites.

O que já não é mais Ciência, mas cientificismo ou positivismo - o sufixo 'ismo' indicando aqui o caráter ideológico e não científico do termo -, é pensarmos que à redução, aos aspectos redutíveis e quantificáveis, corresponde a verdade, ou a verdade total, ou o que interessa do objeto estudado (o que lhe é supostamente essencial). Acredita-se nisso por ingenuidade, por interesses políticos, e/ou por mecanismos defensivos - isto é, por uma necessidade psíquica da crença no mito da 'certeza', a conjurar as inseguranças advindas do mundo mutante que é o da vida.

Quando a Medicina se arvora em se considerar 'científica', em primeiro lugar incorre num erro: ela não é em si científica, mas sim utiliza a Ciência. Em segundo lugar, em geral considera que está do lado da 'verdade', que é uma Medicina verdadeira, que seus dados são verdadeiros ou dizem a verdade, que suas reduções são a verdade (a essência verdadeira) do objeto em questão. Em terceiro lugar, justamente por estes dois pontos anteriores, por julgar-se científica e entender que é verdadeira por isso, em geral a Medicina tende a esquecer que seu 'objeto' é um paciente real, concreto, que ultrapassa em complexidade os esquemas orgânicos, fisiopatológicos, físicoquímicos, que sua 'Ciência' pode abarcar. A Ciência pode ser tida como 'exata', mas o ser humano não o é nem nunca o será. Isso quer dizer que, se abstraímos o mau uso do termo e as más compreensões daí decorrentes, $e$ considerarmos que a Ciência é científica sim, mas apenas no sentido inócuo de que utiliza-se de resultados de pesquisa científica, seguindo métodos considerados atualmente válidos de redução formal, ainda assim somos obrigados a admitir que a Medicina pode ser, nestes termos, científica, mas jamais será somente científica, pois que é também terapêutica. Ou seja, sempre que a Medicina desejar ser terapêutica, tratar um ser humano, considerando-se apenas 'científica', isso não será vantagem nenhuma, mas uma enorme desvantagem, pois o médico que assim sentir e praticar a Medicina certamente estará limitando sua compreensão do processo de saúde e doença, e provavelmente encontrará e mesmo poderá provocar inadvertidamente problemas de ordem psicológica na relação com o paciente, o que tenderá a agravar as condições de saúde deste. Como também o risco de o seu sentimento de onipotência prejudicar sua própria atuação e eficácia estritamente técnicas. 
O poder médico

A crença na Ciência - como toda crença, nada científica - tende a levar o médico que a ela adere consciente ou inconscientemente a assumir uma posição de onipotência diante da dita doença do paciente e, por conseguinte, diante do próprio paciente. Aquele passa a ser visto como devendo necessariamente submeter-se a sua tutela, de modo por vezes incondicional. Algo da ordem de uma abdicação temporária - enquanto for 'seu paciente' de sua autonomia, de seu poder de reflexão sobre si mesmo, de decisão sobre si, de conhecimento intuitivo e, sobretudo, vivencial de si mesmo. Passa a ser visto como um amontoado de órgãos, como uma máquina que 'deu defeito' e que precisa ser reparada segundo o que a Ciência do médico diz. É esta crença na 'verdade científica' que faz com que o médico acredite que pode, ou mesmo deve, se dar ao direito de invadir a autonomia do indivíduo para lhe impor a 'verdade'. Ou, ao menos, o discurso da 'verdade científica' é o que lhe serve de álibi para o exercício de poder sobre o paciente. De um modo ou de outro, este poder é exercido como se fosse de direito, necessário e inevitável - mas não é nem de direito nem necessário para o tratamento; muito pelo contrário, é um fator que contribui para o insucesso de um tratamento, ao menos psiquicamente, e o psiquismo não ajudando somatizações podem se seguir.

Segundo a doutrina da 'verdade científica', o médico passa a ser um guardião da verdade que deve ser imposta ao paciente que, por ter 'pecado', perde todos os seus direitos, e deve ter seu defeito corrigido por aquele que supostamente 'sabe' a verdade sobre o corpo do paciente.

Esta relação de poder fica ainda mais clara quando a prática médico'científica' se dá em hospitais públicos junto a uma população de baixa renda. Esta, já excluída politicamente e socialmente no dia-a-dia da cidade, além de não ter o poder financeiro, em geral não tem estudo superior, não partilhando assim da mesma cultura do médico, nem parecendo àqueles que valorizam a dita 'racionalidade' como alguém digno de ter sua autonomia respeitada. Estes pacientes, além de serem pacientes, tenderão a ver seus direitos de autonomia desrespeitados também por não serem vistos como autônomos mesmo quando não estão na condição de pacientes, parecendo assim duplamente inferiorizados perante a onipotência médica, como sentimento tanto sócio-cultural quanto corporativo.

Em termos mais gerais, o médico positivista, organicista e cientificista é um reflexo de interesses financeiros mundiais, que em nome da Ciência impõem uma medicalização da vida, para fins financeiros. Lucra-se com a venda de remédios, fármacos, drogas, aparelhos de biotecnologia. A saúde torna-se um comércio como outro qualquer. Em nome da Ciência, o médico se sente o arauto da verdade, por vezes mesmo em detrimento da saúde do paciente. Mas em nome da verdade, na realidade torna-se um instrumento de um poder que lucra com sua devoção à causa, e que lhe acena com a devida recompensa financeira - seja com salários ou ganhos importantes, seja com presentes, brindes e viagens, seja simplesmente com um status e uma imagem social elevada.

Na ponta de uma cadeia, operador de um farmacologia de cuja pesquisa em geral não participa, acreditando em pesquisas publicadas em outros 
países, em geral sem ter como aferir a validade de extensão destas para seus pacientes, alienado no domínio de sua própria profissão, virtuose de cirurgias, o médico defronta-se quotidianamente com a morte, a enfermidade, a dor e o sofrimento, as dificuldades sociais de seus pacientes. Distante de compreender os processos sociais, somáticos, psíquicos e existenciais de saúde e doença, divide-se entre lamentar que o curso médico lhe tenha dado apenas um conhecimento técnico do exercício da profissão $e$ não uma visão mais integral e humana da saúde e da enfermidade, ou agarrar-se a esta visão redutora como o que a Psicanálise diagnostica com o nome de defesa maníaca (Winnicott, 2000). Neste caso, o não reconhecimento da autonomia do paciente configura-se como parte integrante da defesa, pois torna-se necessário para confirmar psiquicamente seu sentimento onipotente.

Onipotência no entanto não é potência nem opõe-se à impotência. Ao contrário, onipotência é defesa contra a ameaça de impotência, mas, reativa, mantém esta da qual se quer livrar. Ambas, portanto, impotência e sua máscara a onipotência, se opõem à potência. É somente nesta que nos é possível reconhecer o outro em sua diferença sem considerá-lo inferior ou superior, sendo somente então possível reconhecer-lhe o direito inalienável de sua autonomia.

\section{Medicalização da vida e resistência}

Foucault (1979; 1999) é um dos autores a denunciar o poder médico e a medicalização da vida e da cultura em geral. Esta medicalização se difunde pela mídia e se vale do label de cientificidade para persuadir o público consumidor.

A partir deste 'ideal de saúde', propagado pela mídia e pela indústria médica, qualquer sinal de dor é visto como ultrajante e, portanto, como devendo ser aniquilado; qualquer diferença em relação ao ideal é vista como um desvio, um distanciamento maior, e insuportável, da perfeição colimada, devendo ser 'corrigida'. Os afetos são mobilizados e manipulados narcisicamente no sentido de suscitar nas pessoas o sentimento $e$ a fantasia de que, caso não siga o ideal coletivo da saúde ideal, estará não só aquém da própria saúde ideal apresentada, mas sobretudo fora do grupamento humano atual, será um excluído simbólico, não comungará da moda que une as individualidades atuais e, assim sendo, estará aquém dos outros, dos incluídos que, fantasiosamente, não só gozam de uma saúde próxima do ideal, como, quando não for o caso, terão helicópteros para um último e glamouroso passeio ostentatório.

No mundo do faz-de-conta da saúde ideal, contudo, apesar dos anunciados milagres dos anti-depressivos, da biotecnologia $e$ da Ciência em geral, o paciente sentirá dor, se sentirá enfermo, buscará compreensão por parte do médico e equipe, investidos estes em semi-deuses; e estes em algum momento poderão se auto-medicar em excesso, sentirão dor, ficarão enfermos.

A medicalização da cultura tem como mortos e feridos os pacientes e os próprios médicos. É neste sentido que Foucault (1979, p.97), como vimos, aponta para os ritos religiosos populares como uma espécie de 
resistência difusa à medicalização autoritária de seus corpos e doenças. E nos alerta: "em lugar de ver nessas práticas religiosas um fenômeno residual de crenças arcaicas ainda não desaparecidas, não serão elas uma forma atual de luta política contra a medicalização autoritária, o controle médico?”

No Brasil tais ritos religiosos abundam, como sabemos todos. Seriam crenças arcaicas, anacrônicas, de um passado anterior à Ciência iluminista? Indicariam a sobrevivência de uma crença anterior à crença atual na Ciência? Uma forma 'ultrapassada' de crença, de legitimização, de poder, distantes das formas atuais e dos critérios atuais de instituição do poder?

Ou seriam uma forma de luta política, contra o autoritarismo de um controle médico invasivo e presunçoso? Em tais ritos, os indivíduos, ao serem respeitados em sua autonomia, não teriam ali um ambiente facilitador para melhorarem, reabilitarem-se, recuperar a força, a potência $e$ a firmeza abaladas?

Certo, podemos pensar: ora, troca-se uma crença - na cura trazida pela Ciência - por outra - na cura trazida pela magia, espiritualidade etc.. Entre uma e outra, qual a diferença? Realmente, a reatividade de uma cura total, como a proposta pela Medicina, não se resolve pela reatividade de uma cura mágica. Porém, é preciso entender que o fato de estes tratamentos outros serem tão procurados é um indício de que algo vai mal na proposta oficial. A hipótese de Foucault é que um dos pontos principais é o da falta de autonomia impingida aos pacientes na Medicina oficial, dita científica, seu discurso e sua postura de detentora da Verdade do outro. O que está sendo dito e deve ser ouvido é que, mesmo submetido a práticas mágicas, possivelmente o paciente sente-se ali mais respeitado como pessoa, em sua dignidade ontológica e existencial, inalienável e irredutível. Qual a diferença entre um e outro modo de tratamento? Talvez uma maior autonomia $e$ respeito - e o reconhecimento de que, se é verdade que nós não temos o controle de nosso próprio corpo, e que um tal saber sobre si nos ultrapassa, tampouco outra pessoa, por mais diplomada que seja, o terá.

\section{Compreendendo e conceitualizando a saúde}

O ideal de saúde da Medicina 'científica' - que em geral a define como 'ausência de doença' - segue o famoso modelo cartesiano que concebe o corpo como uma máquina, devendo ser consertada caso dê algum defeito. Este modelo ignora ou menospreza o fato de que não há a tal máquina

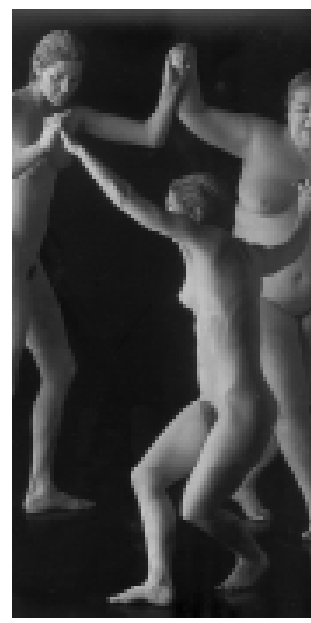
perfeita em relação à qual se saberia que outra estaria defeituosa. Em outras palavras, ignora ou quer ignorar que não existe perfeição, e que nosso corpo não é uma máquina, um mecanismo, mas um complexo vivo e singular. A Ciência, tal como vimos, é bem vinda para obter um conhecimento universalizável deste corpo somatopsíquico complexo e intensivo; mas é igualmente importante entendermos que não somos o resultado da abstração científica, que abstrai singularidades para reter apenas traços muito gerais de nosso corpo. Isso: ao contrário do que se diz, a Ciência trabalha com abstrações. Nosso corpo não se encaixa na abstração da máquina, senão ao preço de grandes perdas.

A Filosofia, que não trabalha com reduções como a Ciência e, portanto, pode abrir mão das abstrações e simplificações da Ciência para permanecer 
na imanência dos corpos, pensando-a em sua singularidade, nos permite compreender o corpo sem ser como uma máquina. Um dos autores que refletiu sobre a saúde foi um médico; um filósofo que, já formado filósofo, cursou a graduação de Medicina e passou a exercê-la, e obteve um Doutorado em Medicina com uma tese filosófica. Refiro-me a Canguilhem (2000) e a sua célebre tese O normal e o patológico, de 1943. Reteremos, para nosso fio de raciocínio, apenas sua idéia central, de que a saúde não se define pela média nem por um ideal, mas por sua plasticidade normativa. A média e o ideal são normalizadores, isto é, morais, impõem uma norma de conduta, de fora para dentro, do universal sobre o singular. Ao contrário, saudável quer dizer, segundo o conceito canguilhemiano, que se tem capacidade para incorporar normas diferentes das até então vigentes, $e$ até mesmo normas patológicas sem se perder a capacidade de ação. Assim, podemos estar enfermos - etimologicamente 'não firmes' - e ainda assim estarmos capazes e saudáveis em diversos outros aspectos de nossa vida ou atividade. Podemos estar fora da média, dos ideais culturais de saúde, mas capazes, ativos.

Espinosa (1992), um filósofo da época de Descartes, mas que se opõe a este pois apresenta uma visão do ser humano como uma unidade somatopsíquica composta de multiplicidades, nos oferece conceitos que podem nos ajudar a construir nosso conceito de saúde. Esta seria vista a partir da idéia de nossa 'potência de agir e de pensar'. Como corpo e mente são vistos como aspectos de nossa unicidade, Espinosa em geral diz apenas 'potência de agir', incluindo nesta a de pensar. Podemos entendê-la, se quisermos, como 'potência de vida', ou como vitalização. A autonomia significa assim criação, auto-criação, autopoiesis: adoecemos porque uma afecção contrária à nossa vitalização baixou nossa potência de vida. Passivos, submergimos a esse pathos, à patologia. É preciso então que reencontremos nossa forma ativa - e não passiva, patológica - de ser, de termos nossa capacidade normativa recuperada.

Um médico pediatra e psicanalista do século XX, Winnicott (1975), também indicava a criação como fonte da saúde pessoal. É preciso que nos sintamos criando o mundo a partir de nossas criações pessoais partilhadas, para que estejamos ativos e vejamos o mundo como nos concernindo. Assim, sentimo-nos expandindo, realizando-nos, vivendo. Ao contrário, em toda situação em que algo nos é imposto como uma verdade pronta, nos sentimos invadidos, impotentes, e aí sim o devir e a vida nos pesam, pois que passam a nos oprimir. Recuperar a saúde, pois, necessita ser algo vivenciado pelo paciente como uma criação sua, para que faça sentido, para que a vitória sobre uma doença seja acompanhada efetivamente de uma recuperação da saúde da pessoa, isto é, que ela possa reapropriar-se de si, reencontrar efetivamente sua capacidade vital, capacidade somatopsiquicamente ativa e criativa em relação à sua vida.

A saúde é assim entendida como algo vivenciado, não passível de redução formal a medições, médias ou normalizações. E será sempre relativa $e$ singular. Daí a importância, da parte de quem se propõe a promover a saúde, do respeito à individualidade daquele que é o receptor de sua ação ou terapia. A relação desigual de poder está desfeita no sentido moral ou 


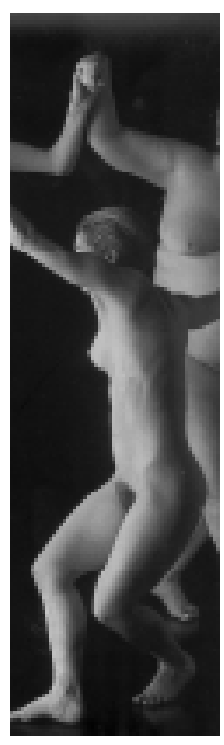

valorativo. A hierarquia que permanece será a de funções, mas aquele que tem o poder de tratar do outro naquele momento, naquela situação terapêutica (e não 'em si'), precisa relacionar-se humanamente de igual para igual com seu paciente, pois não sabe mais dele que ele próprio.

Simplesmente estudou para poder prestar-lhe serviço, e por isso é preciso que haja um entendimento entre as partes em que o médico ou profissional de saúde espera do paciente que este confie nele, para que o profissional possa ajudá-lo, mas não espera que esta confiança seja cega. Afinal, ele não é onipotente, e estará ali apenas esforçando-se para obter sucesso, dando o melhor de si e utilizando a favor de ambos seu aparato técnico, incluindo sempre que for o caso, o aparato científico e tecnológico, que será usado caso o paciente entenda que assim será melhor.

Meu paciente me traz um problema; é preciso que ambos desejem se respeitar mutuamente e colaborar com o outro para o sucesso do tratamento, cujo andamento deverá ser negociado conjuntamente a cada momento crucial, $e$ as decisões que somente o terapeuta poderá tomar deverão ser comunicadas e neste sentido partilhadas com aquele que se submeterá à ação. Afinal, o que está em jogo não é uma saúde ideal, objeto de uma fantasia científica, mas a saúde singular do indivíduo singular que está ali sendo tratado. Do mesmo modo, portanto, quem o trata não é um mandatário da Ciência, mas um profissional singular que está ali.

É neste sentido que Paz Jr. (2002) entende como sendo o objetivo da Medicina não a cura, mas a reabilitação. Assim como entende que a Medicina não deve propriamente tratar doenças, mas doentes. A cura de uma doença tende a corresponder à extinção dos sintomas que indicam um mau funcionamento no organismo pensado não como um todo, mas como uma máquina. Mas a doença pertence ao doente e é o índice de alguma enfermidade que tem o acometimento de algum órgão ou sistema em particular apenas como efeito, não como causa da enfermidade. $O$ objetivo do tratamento do doente passa a ser não a extinção do sintoma somente, mas a reabilitação do indivíduo como um todo, como uma unidade somatopsíquica, como um ser humano enfraquecido que necessita de apoio e tratamento inclusive após a extinção de sintomas, para reencontrar uma potência comprometida. Não 'a mesma' potência de antes, pois a seta do tempo só tem uma direção: trata-se de tornar-se novamente potente, a partir da realidade atual. "Não há retorno a uma inocência biológica", afirma Canguilhem (1943), no sentido de que, justamente por não sermos máquinas, estamos sempre nos transformando, amadurecendo, avançando, sendo o resultado complexo de nossas experiências.

Por fim, esta concepção de saúde também se aproxima do que Nietzsche (2000a, 2000b, 2001) chamara de "a grande saúde". Não se trata de um ideal de perfeição, irreal portanto, que põe a saúde real em débito face a um modelo propagado pela mídia e pela cultura - tal como a idéia perfeita platônica depreciando o mundo real, tomado como sua cópia degradada. Mas, sim, refere-se a uma concepção de saúde que engloba mesmo os momentos de enfermidade, consistindo na força plástica que nos permite ter potência de vida mesmo quando enfraquecidos em algum aspecto. A pequena saúde seria aquela, atrelada a um ideal, em nome da qual deixamos 
de viver. Aquela, tendo medo de perdê-la, não usamos para muita coisa. Neste mesmo sentido, Canguilhem nos lembra que a saúde implica podermos colocá-la em risco. A grande saúde é um resultado final de nossas forças e fraquezas, presente e singular, que vivenciamos quando e sempre que conseguimos potencializar nossa vida mesmo em momentos difíceis.

Se é a saúde vivenciada que importa, e não a saúde de algum 'ideal científico', fica-nos mais claro entender a importância de se reconhecer a autonomia do paciente. Para a grande saúde, é preciso aceitar que a vida é constituída inevitavelmente de dor e

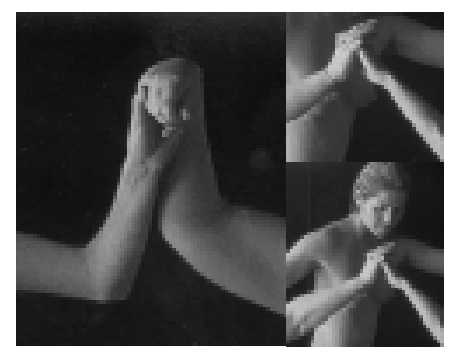
prazer, que o corpo se desgasta inevitavelmente para viver, que a morte é também inevitável, e que é preciso aceitar e elaborar perdas, para poder-se aceitar e aprovar tragicamente a vida; e não fingir que perdas não existem, ou depreciar esta vida em nome de um ideal de imortalidade ou de nirvana, de euforia ou de analgesia. O médico abre mão, assim, da fantasia onipotente de ser um semi-deus armado de uma Ciência supostamente infalível, para conquistar a potência possível, efetiva e humana, de apoiar, com sua técnica e sua arte, outro ser humano num momento de debilidade.

\section{Considerações finais}

Nosso passeio reflexivo e conceitual, de cunho genealógico, nos leva a repensar certos aspectos da Medicina dita científica, tais como a prevenção, por exemplo. Esta não deveria, segundo nosso raciocínio, limitar-se à prevenção alopática de sintomas, mas abranger uma compreensão mais ampla dos fatores que ultrapassam as fronteiras artificiais da abstração orgânica, abrindo-se para os fatores ambientais que influem na capacidade de imunidade metaestável de um indivíduo, este inserido numa coletividade. As próprias fronteiras da Medicina atual estariam assim sendo questionadas pela pergunta quanto ao seu objetivo: se continuará a ser o de curar doenças, ou se passará a ser o de tratar e reabilitar doentes. Neste último caso, deverá deixar de se conceber como representante da verdade para aceitar seu lugar junto a equipes de saúde, discutindo o encaminhamento dos tratamentos em questão junto a outros profissionais de saúde - psicólogos, fisioterapeutas, fonoaudiólogos, nutricionistas, dentistas etc.. A saúde deverá ser pensada e praticada em sua integralidade (Pinheiro \& Mattos, 2003). Mas não apenas isso, também ao ensino médico caberia oferecer aos futuros médicos uma formação em que as disciplinas que enfoquem os aspectos psíquicos e sociais dos processos de saúde e doença sejam mais numerosas e não sejam estigmatizadas como dispensáveis e não-verdadeiras (porque não 'científicas') pelos professores das disciplinas tradicionais. Enfim, será preciso que a Medicina se reassuma como uma arte terapêutica e clínica, mas também que seja mais científica em seu uso da Ciência e, portanto, menos ideológica e moral. O cientificismo e o positivismo não são científicos, mas ideológicos e morais.

Assim, a prevenção se preocuparia em reforçar a imunidade dos pacientes não somente com o auxílio de drogas, mas também ou mesmo sobretudo com o reforço das defesas naturais do próprio corpo do indivíduo, a partir de sua alimentação e do suficiente funcionamento de seus sistemas orgânicos. Do mesmo modo, a promoção à saúde seria enfatizada, sendo no entanto menos 
moral e prescritiva, passando a acreditar mais na capacidade das pessoas em entender o que está em jogo e como podem fazer não para obter mais saúde ideal, mas sim mais saúde efetiva, isto é, como podem aumentar sua potência de agir e de viver.

Da parte dos próprios médicos, são muitos os indícios, sejam negativos ou positivos, de que há algo de errado na prática e no ensino médico oficial. Muitos médicos aderem a medicinas alternativas, aprendidas fora das faculdades de Medicina, mas praticadas dentro de seus consultórios sob a égide da Medicina oficial. Uns tantos médicos se tornam psicanalistas ou seguem uma formação psi para humanizar ou complementar sua formação médica. Uns tantos médicos se drogam na tentativa de sustentar a onipotência imaginariamente exigida deles. Alguns alunos abandonam as faculdades de Medicina por questões existenciais. E muitos médicos se unem a ritos de cura religiosos os mais variados.

Se a medicalização da cultura, se o controle médico sobre o corpo das pessoas, sobre o direito de viver e como viver, sobre o direito de estar doente, de se curar e morrer como quiserem, se impõe a pacientes e a médicos, como em uma dialética do senhor e do escravo, por outro lado são muitas as formas de resistência - formas de sobrevivência, de preservação da autonomia ameaçada pelos outros e por si mesmo, pela subjetividade reinante.

Resistências que não são calculadas ou previstas estrategicamente, mas reações simplesmente defensivas, reatividades, mecanismos defensivos, podendo constituir outras formas de crença, outras cristalizações. Podemos também, no entanto, como profissionais da saúde ou como pessoas, buscar formas criativas de expressão, abrindo brechas em meio aos padrões e práticas reinantes, recriando formas de vida micropoliticamente. As resistências, reativas e não ativas, defensivas e não expansivas, são índices de uma luta, de um conflito de forças, indicam que algo não vai bem na saúde ideal que o mercado apregoa. Que estas sirvam sobretudo de alerta, como um sintoma que indica o adoecimento de um corpo. É imprescindível contudo que possamos dar um passo além, contribuindo para novas práticas e novos valores, novos modos de fazer, de agir, de afetarmo-nos, de conceber e vivenciar o que seja a saúde, a potência de vida e o próprio viver. As resistências lutam pela autonomia a partir do lugar de quem não a tem. É importante passarmos para criações singulares, tanto individuais quanto coletivas, que valorizem a autonomia $e$ abram novos caminhos.

A partir da mensagem trazida pelas formas desconstrutivas de resistência $e$ pelas formas construtivas de recriação, é importante entendermos que, na perspectiva de uma micropolítica, a própria Medicina 'oficial' pode vir a se abrir, a se desencastelar, tendo como guia não as pressões do mercado, mas o objeto mesmo da Medicina: a saúde das pessoas singulares inseridas no mundo - e não a correção de falhas em organismos mecânicos dissociados do mundo. Poderia assim, entender a importância da participação de cada pessoa enferma no processo de reabilitação e reconquista de sua própria saúde.

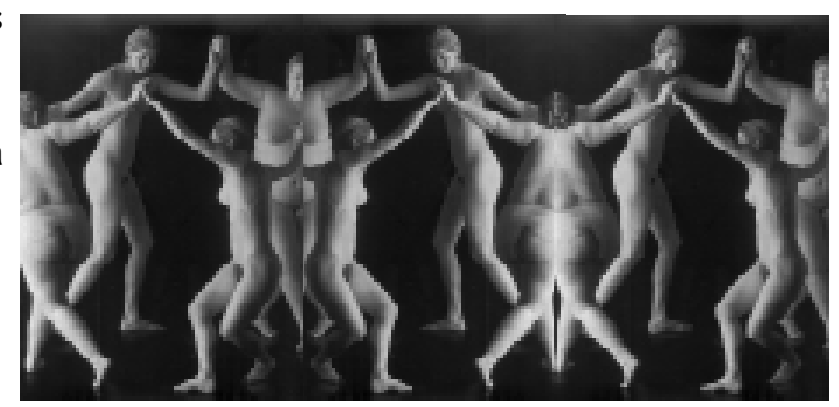

Interface - Comunic., Saúde, Educ., v.8, n.14, p.21-32, set.2003-fev.2004 
MARTINS, A.

\section{Referências}

BITTAR, R. Indústria paga pesquisa pró-amianto: fabricante custeia estudo da Unicamp que vem sendo usado contra o banimento da fibra no país. Valor Econômico, n.113, Brasília, segunda-feira, 09 de outubro de 2000 .

CANGUILHEM, G. O normal e o patológico. Tradução Maria Thereza R. C. Barrocas. Rio de Janeiro: Forense Universitária, 2000.

DELEUZE, G.; GUATTARI, F. O que é filosofia? Tradução Éric Alliez. Rio de Janeiro: Ed. 34, 1992.

ESPINOSA, B. Ética. Tradução Joaquim de Carvalho; Joaquim F. Gomes; Antonio Simões. Lisboa: Relógio d'Água, 1992.

FOUCAULT, M. O nascimento da Medicina Social. Microfísica do poder. Tradução Roberto Machado. Rio de Janeiro: Graal, 1979.

FOUCAULT, M. História da loucura. Tradução José Teixeira Coelho Netto. São Paulo: Perspectiva, 1999.

MARTINS, A. Novos paradigmas e saúde. Physis, v.9, n.1, p.83-112, 1999.

MORIN, E. Ciência com consciência. Tradução Maria Gabriela Bragança; Maria da Graça Pinhão. Sintra: Europa-América, 1994.

MORIN, E. Introdução ao pensamento complexo. Lisboa: Instituto Piaget, 1991.

NIETZSCHE, F. Humano demasiado humano. Tradução Paulo César Souza. São Paulo: Cia. das Letras, 2000a.

NIETZSCHE, F. Nietzsche contra Wagner. Tradução Paulo César Souza. São Paulo: Cia. das Letras, $2000 \mathrm{~b}$.

NIETZSCHE, F. A gaia Ciência. Tradução Paulo César Souza. São Paulo: Cia. das Letras, 2001.

PAZ JR., A. C. Tratando doentes e não doenças. Brasília: Sarah Letras, 2002.

PINHEIRO, R.; MATTOS, R. A. (Orgs) Construção da integralidade: cotidiano, saberes e práticas. Rio de Janeiro: IMS-UERJ/ABRASCO, 2003.

WINNICOTT, D. W. O brincar e a realidade. Tradução José Octávio A. Abreu; Vanede Nobre. Rio de Janeiro: Imago, 1975.

WINNICOTT, D. W. A defesa maníaca: da Pediatria à Psicanálise. Tradução Davy Bogomoletz. Rio de Janeiro: Imago, 2000.

MARTINS, A. Biopolítica: el poder médico y la autonomía del paciente en una nueva concepción de salud, Interface - Comunic., Saúde, Educ., v.8, n.14, p.21-32, set.2003fev.2004.

El presente trabajo busca articular la crítica de Foucault, lo que él llamó "medicalización autoritaria de cuerpos y enfermedades", al concepto de Espinosa de aumento de la potencia de actuar, teniendo como horizonte una reflexión sobre el cuestión de la autonomía de los individuos. Se propone, para esto, reflexionar crítica y genealógicamente sobre el concepto de salud y de cura presentes en la práctica médica actual, así como sobre el poder médico y el concepto mecanicista y cientifista del cuerpo y de la enfermedad relacionada a él. A este concepto, contrapondremos una noción canguilhemiana de salud vinculada a la normativa y de cura vinculada a la rehabilitación. A partir de estos desplazamientos, repensaremos las prácticas médicas actuales, así como los conceptos de promoción de salud y de prevención.

PALABRAS CLAVE: Poder; medicalización; autonomía del paciente; biopolítica; ética. 